UDC 343.1:347.963

Submitted: 10.03.2021

LBC 67.410.201

Accepted: 05.04.2021

\title{
THE PROBLEMS OF IMPLEMENTING THE PROCEDURAL RELATIONSHIP BETWEEN THE PROSECUTOR AND THE INVESTIGATOR ON APPLYING A MEASURE OF RESTRAINT IN JUDICIAL CONTROL PROCEEDINGS (THROUGH THE EXAMPLE OF DETENTION)
}

\author{
Vagip M. Abdrashitov \\ Volgograd State University, Volgograd, Russian Federation \\ Davlatali G. Kakhkhorov \\ Volgograd State University, Volgograd, Russian Federation \\ Violetta D. Gavrilova \\ Volgograd State University, Volgograd, Russian Federation
}

\begin{abstract}
Introduction: the paper examines the problems of implementing the procedural relationship between the prosecutor and the investigator in the course of judicial control proceedings when applying the measures of procedural coercion in the form of detention. In the doctrine of criminal procedure, there are different positions of processualist scientists on improving the criminal procedure activities of the prosecutor and the investigator at the stage of deciding on applying a measure of restraint in the form of detention. The authors took a keen interest in the lack of a legitimate determination of the prosecutor's opinion on the validity and legality of the request of the preliminary investigation bodies to choose detention in the course of judicial control proceedings. It is the written opinion of the prosecutor as a form of intervention at the pre-trial stages, especially in the course of judicial control proceedings when investigating the issue of choosing detention that contributes to the court's taking a legitimate and reasoned decision. In this context, the authors set the goal of finding and improving the efficiency of the procedural model of relations between the prosecutor and the investigator on the issue of resolving a preventive measure in the form of detention in the course of judicial control proceedings.

$\widetilde{\delta}$ Methods: the methodological framework for the study is a set of methods of scientific cognition, among which the main ones are the methods of cognition, comparative law and historical analysis. Results: the authors analyzed the provisions of the criminal procedure norms of the Soviet period on this issue which helped to identify a number of shortcomings in that period and in the present one, which were inherited from the past. Conclusions: the existing procedural model of interaction between the prosecutor and the investigator in a detailed study of the problem of preventive measures in the form of detention, regulated by the current criminal procedure law, does not correspond to the current state policy in relation to the Russian prosecutor, who acts on behalf of the state at all stages of criminal proceedings. In this regard, the authors, based on the analysis of numerous positions of processalist scientists, as well as the judicial and investigative practice, proposed a to procedural model of interaction between the prosecutor and the investigator during the judicial control proceedings, which can be applied in regulating the relationship between the prosecutor and the investigator when considering the issue of applying a measure of restraint in the form of detention.
\end{abstract}

Key words: prosecutor, prosecutor's report, investigator, inquirer, procedural model, judicial control proceedings, detention.

Citation. Abdrashitov V.M., Kakhkhorov D.G., Gavrilova V.D. The Problems of Implementing the Procedural Relationship Between the Prosecutor and the Investigator on Applying a Measure of Restraint in Judicial Control Proceedings (Through the Example of Detention). Legal Concept $=$ Pravovaya paradigma, 2021, vol. 20, no. 2, pp. 57-64. (in Russian). DOI: https://doi.org/10.15688/lc.jvolsu.2021.2.8 


\title{
ПРОБЛЕМЫ РЕАЛИЗАЦИИ ПРОЦЕССУАЛЬНЫХ ВЗАИМООТНОШЕНИЙ ПРОКУРОРА И СЛЕДОВАТЕЛЯ ПО ИЗБРАНИЮ МЕРЫ ПРЕСЕЧЕНИЯ В СУДЕБНО-КОНТРОЛЬНОМ ПРОИЗВОДСТВЕ (НА ПРИМЕРЕ ЗАКЛЮЧЕНИЯ ПОД СТРАЖУ)
}

\author{
Вагип Мнирович Абдрашитов
}

Волгоградский государственный университет, г. Волгоград, Российская Федерация

Давлатали Гаффорович Каххоров

Волгоградский государственный университет, г. Волгоград, Российская Федерация

\section{Виолетта Дмитриевна Гаврилова}

Волгоградский государственный университет, г. Волгоград, Российская Федерация

Введение: в исследуемой статье рассматриваются проблемы реализации процессуальных взаимоотношений прокурора и следователя в ходе судебно-контрольного производства при применении мер процессуального принуждения в виде заключения под стражу. В доктрине уголовного процесса встречаются разные позиции ученых-процессуалистов по совершенствованию уголовно-процессуальной деятельности прокурора и следователя на стадии принятия решения вопроса об избрании меры пресечения в виде заключения под стражу. Пристальный интерес у авторов вызвало отсутствие легитимного определения заключения прокурора на обоснованность и законность ходатайства органов предварительного расследования по избранию заключения под стражу в ходе судебно-контрольного производства. Именно письменное заключение прокурора как форма вмешательства на досудебных стадиях, особенно в ходе судебно-контрольного производства при исследовании вопроса об избрании заключения под стражу, способствует принятию судом законного и обоснованного решения. В этом контексте авторами была поставлена цель по поиску и совершенствованию эффективности процессуальной модели взаимоотношений между прокурором и следователем по вопросу разрешения меры пресечения в виде заключения под стражу в ходе судебно-контрольного производства. Методы: методологическим основанием данного исследования выступает совокупность методов научного познания, среди которых лидирующими позициями представлены методы познания, сравнительно-правового и исторического анализа. Результаты: авторами был сделан анализ положений уголовно-процессуальных норм советского периода по данной проблематике, что способствовало выявлению целого ряда недостатков как в том периоде, так и в настоящем, которые были унаследованы из прошлого. Выводы: имеющаяся процессуальная модель взаимодействия между прокурором и следователем при детальном исследовании проблемы меры пресечения в виде заключения под стражу, регулируемая актуальным уголовно-процессуальным законом, не соответствует современной государственной политике в отношении российского прокурора, который выступает от имени государства на всех стадиях уголовного судопроизводства. В связи с этим авторами на основе анализа многочисленных позиций ученых-процессуалистов, а также судебно-следственной практики, была предложена процессуальная модель взаимодействия прокурора и дознавателя в ходе судебно-контрольного производства, которая может быть применена в регулировании отношения между прокурором и следователем при рассмотрении вопроса об избрании меры пресечения в виде заключения под стражу.

Ключевые слова: прокурор, заключение прокурора, следователь, дознаватель, процессуальная модель, судебно-контрольное производство, заключение под стражу.

Цитирование. Абдрашитов В. М., Каххоров Д. Г., Гаврилова В. Д. Проблемы реализации процессуальных взаимоотношений прокурора и следователя по избранию меры пресечения в судебно-контрольном производстве (на примере заключения под стражу) // Legal Concept = Правовая парадигма. - 2021. - T. 20, № 2. - C. 57-64. - DOI: https://doi.org/10.15688/lc.jvolsu.2021.2.8 


\section{Введение}

Поэтапная реализация судебной реформы в российском уголовном судопроизводстве стала источником появления многих негативных и позитивных нововведений. Так, в связи с выделением такого участника уголовного преследования, как руководитель следственного органа, значительно ограничивались властно-распорядительные полномочия прокурора, осуществляющего уголовно-процессуальную деятельность. В качестве одного из позитивных нововведений можно привести введение института судебно-контрольного производства на досудебных стадиях.

Бесспорно, что судебно-контрольное производство как форма осуществления правосудия на досудебных стадиях является эффективным способом защиты прав и законных интересов участников уголовного дела от необоснованного и незаконного решения. Тем не менее нельзя полностью согласиться с тем, что данный институт может быть единственным доминирующим фактором гарантии законности и обоснованности процессуальных решений участников уголовного преследования на досудебных стадиях. Стоит также акцентировать внимание на роли других публично-властных участников уголовного процесса со стороны обвинения, в частности, прокуро$\mathrm{pa}$, который также обеспечивает законность и обоснованность процессуальных решений следователя (руководитель следственного органа) в судебно-контрольном производстве путем дачи письменного заключения.

Несмотря на многочисленные научные работы, посвященные процессуальному положению участников судебно-контрольного производства, как представляется, все еще недостаточно уделено внимания заключению прокурора, как одному из видов уголовно-процессуального акта.

\section{Современный дискурс} относительно процессуальной модели взаимоотношения прокурора и органов предварительного расследования по избранию заключения под стражу

Так, в ст. 5 УПК РФ, где речь идет об основных понятиях, используемых в тексте закона, к сожалению, нет такого определения, как заключение прокурора. Между тем подпункт 11.1 указанной статьи содержит дефиницию вывода суда, под которой мыслится заключение суда о существовании или об отсутствии в действиях лица, в отношении которого применяется особый порядок производства по уголовному делу, признаков преступления.

Следует отметить, что после внесения изменений в уголовно-процессуальный закон (Федеральный закон от 05.06.2007 г. № 87-Ф3) состав участников судебно-контрольного производства по применению процессуального принуждения в виде заключения под стражу расширился. Иными словами, кроме прокурора, обеспечивающего законность и обоснованность процессуальных решений в ходе судебно-контрольного производства, у следователя (или же руководителя подразделения следственного органа) возникла возможность автономно, вне зависимости от мнения прокурора, защищать собственное мнение перед судом. Однако законодательный орган очередным экспериментальным испытанием не смог довести до логического завершения функциональное значение прокурора в ходе судебноконтрольного производства по избранию меры пресечения в виде заключения под стражу. Не вдаваясь в глубокую полемику, хотелось бы отметить, что в юридической литературе есть существенные аспекты обоснованной критики по данному вопросу [4, с. 53-56].

По нашему мнению, такое неточное законодательное урегулирование процедуры реализации прокурором процессуальной деятельности в судебном заседании и порядок предоставления им письменного заключения о соответствии закону постановления следователя об избрании меры пресечения в виде заключения под стражу привели к разной интерпретации его функционального назначения.

Многие авторы при изучении отдельных локальных актов Генеральной прокуратуры РФ пришли к выводу о том, что прокурор, участвующий в судебно-контрольном производстве по избранию заключения под стражу, обязан представить свое письменное заключение на предмет обоснованности и законности ходатайства следователя [1, с. 75]. Другие авторы такую реализацию прокурором про- 
цессуальной деятельности в судебном производстве считают лишь поддерживанием (или не поддерживанием) ходатайства следователя $[10$, с. 58$]$, а также одним из средств выявления нарушений закона $[15$, с. 70$]$.

Отдельными авторами [14] была выражена идея о том, что действие прокурора в ходе судебного заседания по избранию меры пресечения в виде заключения под стражу является излишним. Они обосновывают свою позицию тем, что прокурор не воздействует на выработку версии расследования и формируемые следователем процессуальные решения.

Важным является то, что национальные суды при детальном анализе постановления следователя об избрании меры пресечения в виде заключения под стражу в отношении подозреваемого (обвиняемого) исходят не из позиции прокурора, выраженной в письменном заключении или постановлении следователя и приложенных к ним материалах уголовного дела, а лишь оценивают вопрос о наличии фактических и юридических оснований $[6$, c. 30 31]. Кроме того, анализ ряда положений Постановления Пленума Верховного Суда РФ от 19.12.2013 № 41 (в ред. от 11.06.2020) удостоверяет, что суд по рассмотрению ходатайства следователя об избрании меры пресечения в виде заключения под стражу должен сообразовывать свои действия с требованиями состязательности и равноправия сторон [9].

В связи с этим многими учеными обоснованно заявляется, что в тех случаях, когда прокурор не поддерживает заявленное органами предварительного расследования ходатайство, суд не должен его удовлетворять, чтобы не нарушать принцип состязательности сторон, так как суд не является органом уголовного преследования, а его представителем выступает именно прокурор [3, с. 44$51 ; 7$, c. $120 ; 12$, c. 207-209].

По этой причине справедливым представляется мнение профессора А.Г. Халиуллина о том, что удовлетворение судом ходатайства следственных органов, не поддержанное прокурором в ходе судебного заседания, является неприемлемым [13, с. 7-8].

Следовательно, мы не можем не согласиться с позицией ряда авторов практического пособия по применению УПК РФ, утверждающих о парадоксальности роли прокурора в ходе судебно-контрольного производства при рассмотрении вопроса об избрании меры пресечения в виде заключения под стражу. Справедливо говорится, что если прокурор удержался от поддержки обвинения в судебном процессе, то такой отказ для суда обязателен, а если прокурор не видит оснований для заключения обвиняемого под стражу, более того, из месяца в месяц, а то и из года в год последовательно утверждает, что последний подлежит освобождению из-под стражи, так как само уголовное дело возбуждено в отношении него незаконно, законодатель снисходительно позволяет суду подобные рассуждения прокурора игнорировать [2].

С нашей точки зрения, обозначенные подходы вышеуказанных авторов имеют право на существование, поскольку прокурор как уполномоченное лицо реализует уголовное преследование от имени государства в уголовном судопроизводстве, в частности, и на досудебных стадиях в ходе судебно-контрольного производства. Это подтверждает тезис о том, что прокурор в своем письменном заключении в ходе судебно-контрольного производства отстаивает не индивидуальные или коллективные интересы определенного субъекта судебного процесса, а государства, доводя до сведения суда доводы законности и обоснованности постановления следователя о возбуждении перед судом об избрании меры пресечения в виде заключения под стражу. Помимо указанного, единственным из числа властно-публичных участников процесса, который в дальнейшем будет обжаловать судебное решение в апелляционном порядке, выступает только прокурор (ч. 1 ст. 389.1 УПК РФ). В связи с этим сложно согласиться с позицией отдельных ученых-процессуалистов, считающих участие прокурора излишним в ходе судебно-контрольного производства по избранию заключения под стражу.

В юридической литературе при разрешении процессуального конфликта интересов между прокурором и следователем в судебно-контрольном производстве по вопросу избрания меры пресечения в виде заключения под стражу сгенерированы разные варианты выхода из данной ситуации.

Одна группа ученых предлагает возвратить процессуальные полномочия прокурора 
по реализации уголовного преследования [4, с. $57-58 ; 11$, с. $63-69 ; 17$, с. $22-26]$.

Другие исследователи инициируют внесение ряда изменений в ст. 108 отечественного уголовно-процессуального законодательства, дефинирующую модель избрания меры пресечения в виде заключения под стражу, а собственно, фиксации обязательства следователя незамедлительно передавать прокурору для ознакомления копий постановления и иных материалов, обосновывающих ходатайство (п. 3.1), а также обязанности суда принять решение об отказе в удовлетворении ходатайства в случае несогласия прокурора с позицией органа предварительного расследования, в ходе судебного заседания на предмет избрания меры пресечения (п. 7.1) [7, c. $121 ; 8$, с. $18-23]$.

\section{Заключение}

Представляется, что предусмотренная уголовно-процессуальным законом процессуальная модель взаимодействия прокурора и дознавателя в процессе избрания меры пресечения в виде заключения под стражу выступает в качестве наиболее эффективного способа устранения нарушений закона. Очевидно, что когда дознаватель с согласия прокурора направляет в суд ходатайство об избрании в отношении подозреваемого (обвиняемого) меры пресечения в виде заключения под стражу, то в данном случае прокурор более глубоко и основательно проинформирован обо всех обстоятельствах дела.

Во-первых, дознаватель направляет прокурору постановление о возбуждении перед судом ходатайства об избрании меры пресечения в виде заключения под стражу с целью согласования. Такое согласование дает возможность прокурору детально изучить все пробелы и устранить все недостатки до отправления дознавателем данного постановления в суд.

Во-вторых, у прокурора, участвующего в судебно-контрольном производстве с целью избрания меры пресечения в виде заключения под стражу, будет достаточно времени для предоставления своего письменного заключения о законности и обоснованности постановления дознавателя.
В-третьих, такая модель взаимодействия ни в коем случае не огранивает полномочия дознавателя, а наоборот, будет способствовать обеспечению реализации сразу нескольких принципов современного уголовного процесса (включая, но не ограничиваясь разумным периодом уголовного судопроизводства, соблюдением законности в ходе расследования уголовного дела, с учетом обеспечения подозреваемому и обвиняемому права на защиту, а также положений презумпции невиновности).

В связи с этим реализация вышепредложенной процессуальной модели взаимодействия между прокурором и следователем (руководителем следственного органа) на этапе решения вопроса об избрании меры пресечения в виде заключения под стражу считается наиболее оптимальным вариантом. Однако не стоит исключать, что данное предложение может породить дискуссии, в том числе и критические замечания, способные оказать конструктивное значение для совершенствования процессуальной модели.

В частности, по мнению И.С. Дикарева, подобная модель взаимоотношения прокурора и сотрудников следственных органов привела бы на практике к возможности вмешательства прокурора в ход предварительного расследования и принятию им решений, не только ограничивающих процессуальную самостоятельность следственного органа, но и подрывающих объективность прокурора (который становился бы сопричастным расследованию лицом) в оценке законности деятельности органов предварительного следствия. Правило такого взаимодействия с прокурором обязано затронуть только случаи направления в суд оконченных производством уголовных дел, и не должно затрагивать порядка обращения в суд с ходатайством об избрании мер пресечения [5].

В таком случае, как справедливо пишут некоторые ученые, прокурор фактически лишается возможности предварительного контроля [7, с. 119], главной задачей которого выступает запрет на получение судом необоснованных и ограничивающих конституционные права и свободы граждан аналогичных ходатайств органов предварительного расследования [16, с. 54-58]. 
Как свидетельствует судебно-прокурорская практика, органы предварительного следствия, вопреки отсутствию оснований избрания рассматриваемой меры пресечения, в судебном заседании всегда стремятся отстаивать свою позицию. К сожалению, суды, несмотря на последовательный отказ прокурора судебного заседания при разрешении задачи об избрании заключения под стражу, иногда удовлетворяют ходатайства органов предварительного следствия, что, на наш взгляд, является необоснованным.

Из этого следует, что изучение научной литературы и анализ правоприменительной практики с момента реализации Концепции судебной реформы РФ до введения в действие отечественного уголовно-процессуального законодательства позволяют сделать вывод о несколько одностороннем подходе при определении роли прокурора в ходе избрания рассматриваемой меры пресечения. Существующая модель взаимодействия участников уголовного судопроизводства, безусловно, нуждается в дальнейшем совершенствовании алгоритма по избранию меры пресечения в виде заключения под стражу.

\section{СПИСОК ЛИТЕРАТУРЫ}

1. Артамонов, А. Н. Полномочия прокурора при надзоре за исполнением законов органами дознания и предварительного следствия / А. Н. Артамонов // Законодательство и практика. - 2016. № 1. - C. $73-80$.

2. Актуальные вопросы судебной практики, рекомендации судей Верховного Суда РФ по применению Уголовно-процессуального законодательства на основе новейшей судебной практики : практ. пособие. В 2 т. Т. 1 / под ред. М. Лебедева. - 7-е изд., перераб. и доп. - М. : Юрайт, 2016. - 231 с.

3. Бажанов, С. В. Прокурорский надзор и судебный контроль в стадии предварительного расследования: повторение ошибок 100-летней давности / С. В. Бажанов // Следственная практика : науч.-практ. сб. Академии Генеральной прокуратуры РФ. - 2016. - Вып. 200. - С. 44-51.

4. Бурмагин, С. В. Метаморфозы состязательности уголовных производств по делам судебного контроля / С. В. Бурмагин // Lex russica. - 2020. T. 73, № 2. - С. 44-62.

5. Дикарев, И.С. Система сдержек и противовесов в досудебном производстве по уголовным делам / И. С. Дикарев // Журнал российского права. -2018 . - № 3. - С. 76-83.

6. Ковтун, Н. Н. К дискуссии об «утраченных» полномочиях прокурора. Есть ли предмет для дискуссий? / Н. Н. Ковтун // Российская юстиция. 2010. - № 5. - C. 29-34.

7. Манова, Н. С. Роль и полномочия прокурора при осуществлении судебно-контрольной деятельности в досудебном производстве / Н. С. Манова // Вестник Удмуртского университета. - 2018. T. 28, № 1. - C. 119-124.

8. Манова, Н. С. Возможно ли принятие судом решения о применении меры пресечения при отказе прокурора поддержать ходатайство следователя? / Н. С. Манова // Российский судья. $-2019 .-$ № 5. - C. 18-23.

9. Постановление Пленума Верховного Суда РФ от 19.12.2013 г. № 41 «О практике применения судами законодательства о мерах пресечения в виде заключения под стражу, домашнего ареста, залога и запрета определенных действий». - Доступ из справ.-правовой системы «КонсультантПлюс».

10. Рябцева, Е. В. Давайте будем последовательны в реформировании уголовного судопроизводства! (О соотношении прокурорского надзора и судебного санкционирования на предварительном следствии) / Е. В. Рябцева // Российская юстиция. -2008 . - № 8. - С. 57-59.

11. Спирин, А. В. Спор между прокурором и следователем в суде недопустим / А. В. Спирин // Юридическая наука и правоохранительная практика. - 2013. - № 4 (26). - С. 63-69.

12. Табакова, М. А. Пробелы правового регулирования учета позиции прокурора при применении заключения под стражу в качестве меры пресечения / М. А. Табакова // Пробелы в российском законодательстве. Юридический журнал. - 2012. № 2. - C. 207-209.

13. Халиуллин, А. Г. Правовое регулирование досудебного производства по уголовным делам нуждается в исправлении системных ошибок / А. Г. Халиуллин // Законы России: опыт, анализ, практика. 2008. - № 11. - C. 3-8.

14. Цветков, Ю. А. Следователь в апелляции / Ю. А. Цветков // Уголовное судопроизводство. 2014. - № 4. - C. 27-32.

15. Шадрин, В. С. Прокурорский надзор за исполнением законов органами дознания и предварительного следствия / В. С. Шадрин // Актуальные проблемы прокурорской деятельности : курс лекций / [В. Г. Бессарабов и др. ; под ред. О. С. Капинус ; рук. авт. кол. Б. В. Коробейников] ; Академия Генеральной прокуратуры Российской Федерации. - М. : Проспект, 2016. - С. 63-79.

16. Шалумов, М. С. Некоторые вопросы, возникающие при рассмотрении судьей ходатайства 
органа предварительного расследования о применении судебного штрафа / М. С. Шалумов // Судья. -2017 . - № 8. - С. 54-58.

17. Щерба, С. П. Дискреционные полномочия прокурора при применении меры пресечения в виде заключения под стражу / С. П. Щерба, А. В. Попова // Законность. - 2016. - № 1. - С. 22-26.

\section{REFERENCES}

1. Artamonov A.N. Polnomochija prokurora pri nadzore za ispolneniem zakonov organami doznanija i predvaritel'nogo sledstvija [Powers of the Procurator in Supervising the Implementation of Laws by the Bodies of Inquiry and Preliminary Investigation]. Zakonodatel'stvo $i$ praktika [Legislation and Practice], 2016, no. 1, pp. 73-80.

2. Lebedev M., ed. Aktual'nye voprosy sudebnoj praktiki, rekomendacii sudej Verhovnogo Suda RF po primeneniju Ugolovno-processual'nogo zakonodatel'stva na osnove novejshej sudebnoj praktiki [Topical Issues of Judicial Practice, Recommendations of Judges of the Supreme Court of the RF on the Application of Criminal Procedure Legislation Based on the Latest Judicial Practice]. Moscow, Yurayt Publ., 2016. 231 p.

3. Bazhanov S.V. Prokurorskij nadzor i sudebnyj kontrol' v stadii predvaritel'nogo rassledovanija: povtorenie oshibok 100-letnej davnosti [Prosecutor's Supervision and Judicial Control in the Preliminary Investigation Stage: Repetition of Errors 100 Years Ago]. Sledstvennaja praktika: nauch.-prakt. sb. Akademii General'noj prokuratury RF [Investigative Practice: Scientific and Practical Collection of the Academy of the Prosecutor General's Office of the RF], 2016, iss. 200, pp. 44-51.

4. Burmagin S.V. Metamorfozy sostjazatel'nosti ugolovnyh proizvodstv po delam sudebnogo kontrolja [Metamorphoses of Adversarial Criminal Proceedings in Cases of Judicial Control]. Lex Russica, 2020, vol. 73, no. 2, pp. 44-62.

5. Dikarev I.S. Sistema sderzhek i protivovesov $\mathrm{v}$ dosudebnom proizvodstve po ugolovnym delam [System of Checks and Balances in Pretrial Criminal Proceedings]. Zhurnal rossijskogo prava [Journal of Russian Law], 2018, no. 3, pp. 76-83.

6. Kovtun N.N. K diskussii ob «utrachennyh» polnomochijah prokurora. Est' li predmet dlja diskussij? [To the Discussion of the "Lost" Powers of the Prosecutor. Is there an Object for Discus?]. Rossijskaja justicija [Russian Justice], 2010, no. 5, pp. 29-34.

7. Manova N.S. Rol' i polnomochija prokurora pri osushhestvlenii sudebno-kontrol'noj dejatel'nosti $\mathrm{v}$ dosudebnom proizvodstve [Role and Powers of the Prosecutor in the Conduct of Judicial Control Activities in Pre-Trial Proceedings]. Vestnik Udmurtskogo universiteta [Bulletin of Udmurt University], 2018, vol. 28, no. 1, pp. 119-124.

8. Manova N.S. Vozmozhno li prinjatye sudom reshenija o primenenii mery presechenija pri otkaze prokurora podderzhat' hodatajstvo sledovatelja? [Is it Possible that the Court's Decisions on the Application of the Preventive Measure in Case of the Prosecutor's Refusal to Support the Investigator's Request?]. Rossijskij sud'ja [Russian Judge], 2019, no. 5, pp. 18-23.

9. Postanovlenie Plenuma Verhovnogo Suda RF ot 19.12 .2013 g. № 41 «O praktike primenenija sudami zakonodatel'stva o merah presechenija $\mathrm{v}$ vide zakljuchenija pod strazhu, domashnego aresta, zaloga i zapreta opredelennyh dejstvij» [Resolution of the Plenum of the Supreme Court of the RF of 19.12.2013 no. 41 "On the Practice of the Courts Applying Legislation on Preventive Measures in the Form of Detention, House Arrest, Bail and Prohibition of Certain Actions"]. Access from Reference Legal System "KonsultantPlyus".

10. Rjabceva E.V. Davajte budem posledovatel'ny $\mathrm{v}$ reformirovanii ugolovnogo sudoproizvodstva! (O sootnoshenii prokurorskogo nadzora i sudebnogo sankcionirovanija na predvaritel'nom sledstvii) [Let's be Consistent in Reforming the Criminal Court of Procedure! (On the Ratio of Prosecutorial Supervision and Judicial Authorization on Preliminary Investigation)]. Rossijskaja justicija [Russian Justice], 2008, no. 8, pp. 57-59.

11. Spirin A.V. Spor mezhdu prokurorom i sledovatelem v sude nedopustim [The Dispute Between the Prosecutor and the Investigator in Court is Inadmissible]. Juridicheskaja nauka $i$ pravoohranitel'naja praktika [Legal Science and Law Enforcement Practice], 2013, no. 4 (26), pp. 63-69.

12. Tabakova M.A. Probely pravovogo regulirovanija ucheta pozicii prokurora pri primenenii zakljuchenija pod strazhu v kachestve mery presechenija [Gaps in the Legal Regulation of Taking into Account the Position of the Prosecutor in the Application of Detention as a Preventive Measure]. Probely v rossijskom zakonodatel'stve. Juridicheskij zhurnal [Gaps in Russian Legislation. Legal Journal], 2012, no. 2, pp. 207-209.

13. Haliullin A.G. Pravovoe regulirovanie dosudebnogo proizvodstva po ugolovnym delam nuzhdaetsja v ispravlenii sistemnyh oshibok [Legal Regulation of Pre-Trial Criminal Proceedings Needs Correction of Systemic Errors]. Zakony Rossii: opyt, analiz, praktika [Laws of Russia: Experience, Analysis, Practice], 2008, no. 11, pp. 3-8.

14. Cvetkov Ju.A. Sledovatel' v apelljacii [Investigator on Appeal]. Ugolovnoe sudoproizvodstvo [Criminal Proceedings], 2014, no. 4, pp. 27-32. 


\section{ГЛАВНАЯ ТЕМА НОМЕРА}

15. Shadrin V.S. Prokurorskij nadzor za ispolneniem zakonov organami doznanija i predvaritel'nogo sledstvija [Procuratorial Supervision of the Implementation of Laws by the Bodies of Inquiry and Preliminary Investigation]. Kapinus O.S., ed. Aktual'nye problemy prokurorskoj dejatel'nosti [Current Problems of Prosecutorial Activity]. Moscow, Prospekt Publ., 2016, pp. 63-79.

16. Shalumov M.S. Nekotorye voprosy, voznikajushhie pri rassmotrenii sud'ej hodatajstva organa predvaritel'nogo rassledovanija o primenenii sudebnogo shtrafa [Some Issues that Arise when the Judge Considers the Application of the Preliminary Investigation Body for a Court Fine]. Sud'ja [Judge], 2017, no. 8, pp. 54-58.

17. Shherba S.P., Popova A.V. Diskrecionnye polnomochija prokurora pri primenenii mery presechenija $\mathrm{v}$ vide zakljuchenija pod strazhu [Discretionary Powers of the Prosecutor in the Application of the Preventive Measure of Detention]. Zakonnost' [legality], 2016, no. 1, pp. 22-26.

\section{Information About the Authors}

Vagip M. Abdrashitov, Doctor of Sciences (Jurisprudence), Professor, Department of Theory and History of Law and State, Volgograd State University, Prosp. Universitetsky, 100, 400062 Volgograd, Russian Federation, abdrashitov@volsu.ru, https://orcid.org/0000-0003-4058-0428

Davlatali G. Kakhkhorov, Senior Lecturer, Department of Criminal Procedure and Criminalistics, Volgograd State University, Prosp. Universitetsky, 100, 400062 Volgograd, Russian Federation, kahhorov@volsu.ru, https://orcid.org/0000-0003-1622-9339

Violetta D. Gavrilova, Student, Institute of Law, Volgograd State University, Prosp. Universitetsky, 100, 400062 Volgograd, Russian Federation, SPD-201_252364@volsu.ru, https://orcid.org/0000-0003-1537-6126

\section{Информация об авторах}

Вагип Мнирович Абдрашитов, доктор юридических наук, профессор кафедры теории и истории права и государства, Волгоградский государственный университет, просп. Университетский, 100, 400062 г. Волгоград, Российская Федерация, abdrashitov@volsu.ru, https://orcid.org/0000-0003-4058-0428

Давлатали Гаффорович Каххоров, старший преподаватель кафедры уголовного процесса и криминалистики, Волгоградский государственный университет, просп. Университетский, 100, 400062 г. Волгоград, Российская Федерация, kahhorov@volsu.ru, https://orcid.org/0000-0003-1622-9339

Виолетта Дмитриевна Гаврилова, студент Института права, Волгоградский государственный университет, просп. Университетский, 100, 400062 г. Волгоград, Российская Федерация, SPD-201_252364@volsu.ru, https://orcid.org/0000-0003-1537-6126 